\title{
DIFICULDADES DOS ESTUDANTES DE ENFERMAGEM, FRENTE AOS DOENTES MENTAIS INTERNADOS
}

\author{
Ilza Marlene Kuae Fukuda* \\ Dra. Evalda Cançado Arantes*
}

\begin{tabular}{l|c|}
\cline { 2 - 2 }$/ 05$ \\
\hline
\end{tabular}

FUKUDA, I.M.K. e ARANTES, E.C. - Dificuldades dos estudantes de enfermagem, frente aos doentes mentais internados. Rev. Bras. Enf.; DF, $28: 48-63,1976$.

\section{INTRODUÇĀO}

Recorrendo-se à literatura especializada e analisando-se as vivências diárias com estudantes que assistem doentes mentais, percebe-se que os alunos, ao iniciarem o estágio em Enfermagem Psiquiátrica, trazem consigo muitas idéias preconcebidas acerca daqueles doentes. Além disso, no começo da interação com os pacientes, surgem dificuldades, ocasionadas pelo tipo de comunicação oferecida pelos enfermos.

A identificação dos problemas do paciente, oriundos de sua sintomatologia, é o primeiro passo, ao planejar-se uma assistência de enfermagem. Contudo, há diversos fatores que, de uma forma ou de outra, levam a enfermeira a sentir dificuldade na identificação, compreensão e tentativa de solução objetiva dos problemas do doente. Esse embaraço ocorre, porque ambos - enfermeira e paciente - têm sua própria personalidade, sentimentos e necessidades. Orientando estudantes na elaboração de planos de assistência de enfermagem psiquiátrica, observa-se que também eles acham dificil fazer aquela importante identificação.

Por tudo isso, resolveu-se elaborar o presente estudo, para verificar quais as dificuldades encontradas pelos alunos, no convívio com os doentes mentais.

\section{Objetivos}

1. Realizar o levantamento das dificuldades dos estudantes:

a) no relacionamento terapêutico com os doentes mentais;

b) na elaboração do plano de assistência de enfermagem.

2. Elaborar um programa de orientação para os estudantes, tendo em vista as dificuldades encontradas.

Revisão de literatura

Segundo HOFLING et a1. (1972), a assistência de enfermagem é sempre prestada numa situação interpessoal. em que estão envolvidas duas pessoas: a enfermeira e o paciente. Ambos têm sentimentos e necessidades, que são expres-

* Docentes de Enfermagem Psiquiátrica, na Escola de Enfermagem da USP. 
F'UKUDA, I.M.K. e ARANITES, E.C. - Dificuldades dos estudantes de enfermagem, frente aos doentes mentais internados. Rev. Brs. Enf.; DF, $28: 48-63,1976$.

sos de diferentes maneiras. responsabilidade da enfermeira, compreender sua própria personalidade e a influência que tem sobre os demais; não deve usar o paciente, para a satisfação de suas necessidades. Para IRVING (1973), a enfermeira não é um tipo particular de personalidade, um autômato encarregado de executar serviços ou um acumulado de qualidades especiais. Deve ser uma pessoa emocionalmente madura, suficientemente capaz de adiar as satisfaçōes das próprias necessidades e de permitir que o paciente tenha precedência na satisfação das suas. Segundo STEVENS (1957) e BISCHOFF \& CONNOLLY (1951), a compreensão do próprio comportamento é condição básica para a compreensão do comportamento do outro. MADDISON (1970) diz que, em resumo, o cuidado de enfermagem, em Enfermagem Psiquiátrica, consiste no reconhecimento e atendimento das necessidades do paciente.

GARANT (1972) afirma que a observação e o relato escrito do comportamento do paciente são essenciais para se identificarem seus problemas e necessidades não-satisfeitas. Como professora de enfermagem psiquiátrica, observou que muitos dos planos apresentados eram pobres, quando não, um aglomerado de juízos de valores; e diz que, ao elaborar um plano de culdados, a enfermeira deve estar consciente de seus sentimentos e da influência destes, na identificação das necessidades dos pacientes.

ROBINSON (1972) aborda a situação, não rara, na qual o estudante teme trabalhar com pacientes psiquiátricos. Analisa-a e conclui que uma das causas desse temor poderia ser atribuída ao medo, que os estudantes sentem, de ferir emocionalmente as pacientes ou de serem feridos por eles.

KIMBALL (1958) assegura que podem surgir muitos problemas pessoais, quando a estudante atua em uma unidade psiquiátrica. Ela pode resistir a cuidar de pacientes com certos tipos de comportamento (como, por exemplo, pacientes agressivos ou que demonstrem host1lidade), uma vez que estes lhe causam medo.

ALBIEZ (1970) observou que, quando - estudante de enfermagem inicia seu estágio em hospital psiquiátrico, traz consigo medo - idéía falsa e preconceito comum ao público em geral - a respeito dos doentes mentais com que Irá trabalhar. Ressalta que aceitar o paciente como ele é, sem julgá-lo de acordo com os próprios padrōes de comportamento, é um fator-chave no relacionamento terapêutico. MULLER (1962) refere que o aluno, ao iniciar sua aprendizagem em Enfermagem Psiquiátrica, traz uma bagagem de conhecimentos errôneos acerca das pessoas; além disso, os preconceitos em relação à doença mental freqüentemente o impedem de perceber as coisas realisticamente. Isso interfere na sua tentativa de desenvolver um relacionamento efetivo com o paciente.

HUGHIE (1967) considerou que o aparecimento de um ou mais dos seguintes sentimentos: culpa, pena, medo, ansiedade, hostilidade, embaraço, repulsa, depressão, desesperança e rejelção provocam sensação de desconforto, nos membros da equipe de enfermagem. Fez um estudo com 17 desses membros, para determinar os tipos de comportamento dos pacientes responsáveis pelo aparecimento do maior número de situaçōes de desconforto, e concluiu que predominam as ligadas às dificuldades de comunicaçăo e à expressão de hostilidade.

BLACK (1952), BRILL (1957), LEWIS (1960) e MADDISON (1970) concordam em que a personalidade da enfermeira e o uso que faz de si mesma são fatores valiosos no cuidado do paciente. $A$ mals poderosa droga e o mais alto grau de habilidade perdem sua total eficácia, se a enfermeira não fizer uso inteligente de si. Contudo, ela, como qualquer pessoa, 
FUKUDA, I.M.K. e ARANTES, E.C. - Dificuldades dos estudantes de enfermagem, frente aos doentes mentais internados. Rev. Bras. Enf.; DF, 28: 48-63, 1976.

tem seus probemas e, só após reconhecêlos, estará capacitada para identificar os dos outros.

Em relação às enfermeiras que se iniciam em Enfermagem Psiquiátrica, MERENESS (1970) verificou que elas podem sentir medo de prejudicar física e emocionalmente o paciente; de não saber atuar profissionalmente; de perder o controle emocional e de serem rejeitadas. Acha que, caso a enfermeira venha a sentir-se oprimida, amedrontada e ansiosa, terá dificuldade para concentrar sua atenção e interesse nos problemas do paciente. Então deve identificar a origem de seu medo e ansiedade, para lutar contra tais reaçōes. De outra maneira, a enfermeira será incapaz de atuar terapeuticamente.

WALLACE (1968) cita que também a enfermeira especializada, em conseqüência de seus próprios medos e ansiedades, pode agredir emocionalmente um paciente, embora saiba que ele sofre com sua doença.

ROBINSON (1972) refere que, com o autoconhecimento, a enfermeira chega à conclusão de que o receio sentido por ela representa, na realidade, o medo do desconhecido, o de não ser capaz de atuar na especialidade. Para LEWIS (1960), um dos sentimentos mais freqüentes na enfermeira é a ansiedade, e esta pode originar-se de diversas fontes: entre outras a apreensão em relação ao comportamento do paciente e o temor da própria incapacidade na atuação junto a ele. Geralmente, a origem da ansiedade não é conhecida.

Para BROWN \& FOWLER (1971), as reaçōes para com certas pessoas, lugares ou objetos são provocadas pelas atitudes. Declara que, quando certos doentes são repulsivos para nós, estamos prontos a comunicar essa repulsa, de forma nãoverbal, durante assistência de enfermagem. De modo geral, as pacientes percebem esta atitude negativa em relação a eles, apesar de não estarmos conscientes disso.

TUTER (1956) julga que a experiência em Enfermagem Psiquiátrica é uma tarefa difícil, pelo estigma que sempre pesou (e ainda pesa) sobre os doentes mentais, e que o impacto será inevitável no primeiro encontro com eles. A enfermeira defrontará com pedidos que lhe parecerão irracionais; então, umas vezes, poderá haver sentimento de compaixão em tal intensidade que a incapacitará para a identificação de certas necessidades do paciente; outras vezes, poderá haver comparação do comportamento do doente com o de outras pessoas, que se comportavam de modo inadequado e desagradável. Qualquer dessas reações será nociva e prejudicará muito o trabalho, tão difícil, da enfermeira. A fim de que a sua atuação seja satisfatória, será necessário que ela se desfaça de todas as idéias e preconceitos, que recaem sobre os doentes mentais, e que mantenha a mente aberta para aliviá-los como pessoas que estão precisando de ajuda. Para BROWN \& FOWLER (1971), a mudança desta atitude apenas ocorrerá, no instante em que a enfermeira se tornar consciente de seus verdadeiros sentimentos e verificar quando e em que circunstâncias eles surgem. Só assim, podem ser desenvolvidas habilidades no sentido de estabelecer um relacionamento terapêutico eficaz.

\section{Método}

\section{a) População}

O estudo foi realizado, a partir de 1972 , com alunos do $3 .^{\circ}$ ano do Curso de Graduação em Enfermagem, quando cursavam a disciplina Enfermagem Psiquiátrica.

b) Técnica.

1. Pretendendo que não houvesse qualquer interferência nas idéias trazi- 
FUKUDA, I.M.K. e ARANTES, E.C. - Dificuldades dos estudantes de enfermagem, frente aos doentes mentais internados. Rev. Bras. Enf.; DF, 28 : 48-63, 1976.

das pelos estudantes, utilizou-se um questionário aberto, no primeiro dia de aula, para identificar seus sentimentos em relação aos doentes mentais (Anexo I).

Nas duas primeiras semanas do curso, o programa desenvolvido consistiu em aulas teóricas e práticas, que focalizaram a observação e a descrição do comportamento apresentado pelo paciente. Após esse periodo, teve início o relacionamento terapêutico.

2. Durante a quarta semana (quando o aluno tem oportunidade e capacidade de reconhecer seus sentimentos frente ao paciente e quando começa a envolver-se terapeuticamente), foi aplicado um outro questionário aberto (Anexo 2), para identificar os sentimentos do estudante a respeito do doente.

3. Ainda no decorrer da quarta semana, deu-se, aos estudantes, uma orientação (Anexo 3) sobre as dificuldades gerais e foi-lhes solicitado um plano de assistência de enfermagem, a ser entregue às professoras para correção e posterior comentário. Forneceu-se um modelo (Anexo 4), com o objetivo de uniformizar a sua apresentação.

4. Na sexta semana (quando o relacionamento terapêutico está em franco desenvolvimento e há maior conhecimento pessoal de ambas as partes estudante e paciente), aplicou-se um terceiro questionário aberto (Anexo 5). para identificar os sentimentos do aluno em relação aos pacientes.

Todos os questionários foram aplicados apenas aos estudantes presentes, no momento, na sala de aula, informandose-lhes que os questionários se destina- vam a uma pesquisa - motivo por que eles poderiam deixar de identificar-se, ou mesmo de respondê-los, se assim o desejassem.

Definição de termos

\section{Relacionamento terapêutico}

O "relacionamento terapêutico" envolve duas pessoas, sendo uma delas profissional - a enfermeira, que possui a capacidade de ajudar - e a outra, o paciente, que busca alivio para algum problema. O relacionamento exige que a enfermeira desempenhe seu papel, utilizando os conhecimentos e habilidades profissionais em favor do bem-estar físico, social e emocional do paciente (1)

\section{Sentimento}

"Sentimento" refere-se a sistema de tendências emocionais ligadas à idéia de certo objeto e organizadas em torno dele (2).

\section{Resultados e comentários}

Como os três questionários foram apl:cados em épocas diferentes e como os estudantes poderiam ou não respondêlos, obteve-se número desigual de respostas nas três ocasiōes. Além disso, os questionários eram abertos e permitiam respostas múltiplas.

Na primeira pergunta do primeiro questionário (Anexo 1), obtiveram-se 77 respostas, que expressam o que pensam os estudantes em relação aos doentes mentais. Através delas, identificaram-se as idéias, que os estudantes têm, da pessoa desses pacientes (Quadro 1).

(1) HOFWNG, C.K. et al. Basic psychiatric concepts in nursing. 2 ed., Philadelphia, J.B. Linnincott. 1972. p. 31 .

(2) PIFrsoN, D. Tearia e pesquis em sociologia. 13. ed., Såo Paulo, Melhoramentos, 1971. p. 330. 
FUKUDA, I.M.K. A ARANTSS, E.C. -- Dificuldades dos estudantes de enfermagem, frente a0s doentes mentais internados. Rev. Bras. Enf.; DF, 28 : 48-63, 1976.

QUADRO 1

ID AIAS DE 50 ESTUDANTES A RESPEITO DOS DOENTES MENTAIS

\begin{tabular}{lrr}
\hline \multicolumn{1}{c}{ IDfiras } & \multicolumn{2}{c}{ Respostas } \\
& N.0 & $\%$ \\
\hline Agressivos e perigosos & 19 & 24,7 \\
Com distúrbio de comportamento, de ação imprevisível & 18 & 23,4 \\
Fora da realidade & 8 & 10,4 \\
Incapazes de relacionar-se com as pessoas, dizem ou fazem coisas & & \\
$\quad$ sem lógica, descontrolados & 7 & 9,1 \\
Carentes de compreensão, aceitação e atenção, massacrados e rejei- & 6 & 7,8 \\
$\quad$ tados pela sociedade, desadaptados ao meio, infelizes & 3 & 3,9 \\
Irrecuperáveis & 2 & 2,6 \\
Incapazes para qualquer atividade, apáticos & 2 & 2,6 \\
Mais sensiveís que os demais, não gostam de ser contrariados & 1 & 1,3 \\
Débeis mentals & 11 & 14,2 \\
(Idéias indefinidas* ) & 77 & 100,0 \\
\hline TOTAL & & \\
\hline
\end{tabular}

- No Anexo 6, estão apresentadas as respostas em que houve idéias indefinidas

e as que se referiram a distúrbio de comportamento.

HUGHIE (1967) verificou que os tipos de comportamento de pacientes que causavam desconforto no pessoal de enfermagem estão contidos em quatro grupos de situaçōes: limitaçōes de comportamento, situações que envolvem contato físico, dificuldades de comunicação e expressōes de hostilidade. Pelas respostas dos estudantes, verifica-se que $67,6 \%$ das mesmas (quatro primeiros grupos de idéias) poderiam enquadrar-se no último caso (expressão de hostilidade) e, portanto, ser consideradas geradoras de ansiedade.

Em resposta à segunda pergunta do primeiro questionário (Anexo 1) e às perguntas do segundo e terceiro questionários (Anexo 2 e 5) sobre os sentimentos dos estudantes em relação aos doentes mentais, foram citadas expressōes de sentimentos que estão apresentados no Quadro 2.

\section{QUADRO 2}

SENTIMENTOS EXPRESSOS PELOS ESTUDANTES EM RELAÇAOO AOS DOENTES MENTAIS, NO PRIMEIRO DIA DE AULA, NA QUARTA E NA SEXTA SEMANAS DO CURSO DE ENFERMAGEM PSIQUIATRICA

\begin{tabular}{|c|c|c|c|c|c|c|}
\hline \multirow{2}{*}{$\begin{array}{l}\text { SENTIMENTOS } \\
\text { EXPRESSOS }\end{array}$} & \multicolumn{2}{|c|}{$\begin{array}{l}1.0 \text { dia de aula } \\
\text { RESPOSTAS }\end{array}$} & \multicolumn{2}{|c|}{$\begin{array}{c}4 .^{8} \text { semana } \\
\text { RESPOSTAS }\end{array}$} & \multicolumn{2}{|c|}{$\begin{array}{c}6 .{ }^{8} \text { semana } \\
\text { RESPOSTAS }\end{array}$} \\
\hline & N.o & $\%$ & N.O & $\%$ & N.o & $\%$ \\
\hline Ansiedade & 29 & 37,2 & 22 & 30,5 & 3 & 7,1 \\
\hline Pena & 21 & 26,9 & 26 & 36,1 & 12 & 28,6 \\
\hline Aceitação & 4 & 5,1 & 12 & 16,7 & 18 & 42,8 \\
\hline Rejeição & 4 & 5,1 & 3 & 4,2 & 1 & 2,4 \\
\hline Curiosidade & 6 & 7,7 & - & - & - & - \\
\hline (Sentimentos indefinidos) & 14 & 18,0 & 9 & 12,5 & 8 & 19,1 \\
\hline TOTAL & 78 & 100,0 & 72 & 100,0 & 42 & 100,0 \\
\hline
\end{tabular}


FUKUDA, I.M.K. e ARANTSS, E.C. - Dificuldades dos estudantes de enfermagem, frente aos doentes mentais internados. Rev. Bras Enf.; DF, $28: 48-63,1976$.

Para tabulação dessas expressões, usouse a classificação apresentada no Anexo 7.

Pela análise dos dados apresentados no Quadro 1, já era esperado que a ansiedade fosse o sentimento expresso no maior número de respostas dadas pelos estudantes no primeiro dia de aula: $37,2 \%$. Contudo, deve-se considerar que, no decorrer do relacionamento terapêutico com o paciente, a ansiedade diminuiu: fol para $30,5 \%$ na quarta semana e quase desapareceu na sexta: 7,1\%. Essa evolução é natural, porque, nessa fase do curso, os estudantes já estão familiarizados com os pacientes e têm maior conhecimento teórico da disciplina - fato que lhes permite mais segurança no relacionamento com os doentes.

O sentimento pena foi identificado em $26,9 \%$ das respostas dadas pelos estudantes no primeiro dia de aula. Porém, na quarta semana do curso, a percentagem aumentou para $36,1 \%$, talvez pelo envolvimento do estudante com 0 paciente, que é característica desta fase do relacionamento. Ainda na sexta semana, a percentagem manteve-se em nível elevado: $28,6 \%$, o que pode ser, de certa forma, explicado pelas características do hospital - escola que os alunos freqüentam - hospital fechado, sem espaços adequados para recreação e laborterapia. Enquanto a rejeiçáo do paciente pelo estudante decresce, a aceitação cresice de $5,1 \%$ para $42,8 \%$.

A curiosidade, que no inicio representava 7,7\% das respostas, desaparece completamente a partir da quarta semana.

Apesar de ter sido grande o número de respostas com sentimentos indefinidos, não se pôde tratar os dados de outra forma, pois, do contrário, se cairia no terreno das interpretaçōes infundadas.

A terceira pergunta do primeiro questionário (Anexo 1) versa sobre a expectativa da primeira experiência com os pacientes internados. As 25 respostas obtidas de 25 estudantes (Anexo 9) expressaram o que fol considerado manifestação de ansiedade, exceção feita de uma, na qual se julgou imprecisa a expressão de sentimento.

A quarta pergunta do primeiro questionário (Anexo 1), em que se indaga, diretamente, se houve algum contato com doente mental, foi respondida por 57 estudantes. Destes, $24(42,1 \%)$ responderam afirmativamente e $33(57,9 \%)$, negativamente. Dos primeiros, 23 descreveram a situação em que se deu o contato (Quadro 3) e essa descriçāo, pormenorizada, está contida no Anexo 8.

\section{QUADRO 3}

RELAÇOES DE 24 ESTUDANTES AO CONTATO COM O DOENTE MENTAL

\begin{tabular}{lrr}
\hline REAÇOES DOS ESTUDANTES & \multicolumn{2}{c}{ RESPOSTAS } \\
\cline { 2 - 3 } & N.0 & $\%$ \\
\hline Medo & 9 & 37,5 \\
Pena & 3 & 12,5 \\
Afirmação de experiência positiva & 2 & 8,3 \\
(Reação indefinida) & 9 & 37,5 \\
(Não respondeu) & 1 & 4,2 \\
\hline TOTAL & & \\
\hline
\end{tabular}


FUKUDA, I.M.K. e ARANTES, E.C. - Dificuldades dos estudantes de enfermagem, frente aos doentes mentais internados. Rev. Bras. Enf.; DF, $28: 48-63,1976$.

As respostas consideradas como expressão de ansiedade (Quadros 1 e 2) refletem uma reação infundada por parte dos alunos, uma vez que, dos 57 estudantes, 24 afirmaram que tiveram contato prévio com doente mental e, destes, apenas $9(15,8 \%)$ afirmaram haver sentido medo nessa situação. O restante - $48(84,2 \%)$ - não se viu, com o doente mental, em condiçōes que justificas- sem o aparecimento do medo ou de outro sentimento capaz de gerar ansiedade.

Os estudantes citaram as suas dificuldades, conforme pedido feito do próprio plano de assistência de enfermagem (Anexo 4). Essas dificuldades foram agrupadas no quadro a seguir (Quadro 4) e sua descrição, pormenorizada, está contida no Anexo 10.

\section{QUADRO 4}

\section{DIFICULDADES CITADAS PELOS ESTUDANTES NOS PLANOS DE ASSISTENCIA DE ENFERMAGEM}

\begin{tabular}{lrr}
\hline DIFICULDADES & \multicolumn{2}{c}{ RESPOSTAS } \\
\cline { 2 - 3 } & N.0 & $\%$ \\
\hline Dificuldades dos estudantes relativas ao seu estado emocional e & & \\
$\quad$ conhecimento & 25 & 56,8 \\
Dificuldades dos estudantes relativas ao comportamento do paciente & 19 & 43,2 \\
\hline TOTAL & 44 & 100,0
\end{tabular}

$O$ fato de $56,8 \%$ das dificuldades dos estudantes, na elaboração do plano de assistência de enfermagem, estarem ligadas a eles próprios vem confirmar a afirmação de GARANT (1972) de que a "enfermeira deve, também, considerar as suas próprias atitudes e sentimentos em relação ao paciente e verificar quais os efeitos que têm, na sua habilidade de identificar e satisfazer as necessidades do paciente. Ela precisa estar consciente de como seu próprio comportamento afeta outrem e como é afetado pelas outras pessoas".

Ao iniciar-se o estudo, tinha-se em mente que, se fosse possivel fazer-se uma orientação geral e que eliminasse a ansiedade dos estudantes, não seria necessária uma orientação contínua e individualizada dos mesmos; dessa for- ma, haveria economia no tempo das docentes. Em vista, porém, das dificuldades sentidas pelos estudantes, viu-se que tal econcmia se torna impossível.

\section{CONCLUSOEES}

O levantamento das dificuldades dos estudantes, no relacionamento com os doentes mentais, informou que os alunos trazem consigo idéias preconcebidas. De acordo com o estudo realizado, $42,1 \%$ dos 57 estudantes tiveram contato prévio com doentes mentais; $15,8 \%$ apresentaram reação de medo, quando, na resposta inicial, apareceram $37,2 \%$ de ansiedade.

As dificuldades dos estudantes, na elaboração do plano de assistência de enfermagem, estão ligadas a eles próprios, 
FUKUDA, I.M.K. e ARANTSS, E.C. - Dificuldades dos estudantes de enfermagem, frente aos doentes mentais internados. Rev. Bras. Enf.; DF, $28: 48-63,1976$.

em $56,8 \%$ dos casos; em $43,2 \%$, relacionam-se com o comportamento do paciente.

Os elementos identificados podem servir de base ao preparo de um programa de orientação para os estudantes que iniciam o curso de Enfermagem Psiquiátrica, de forma a minorar a ansiedade inicial que os afeta.
No começo da pesquisa, tinha-se em mente fazer uma orientação geral capaz de eliminar a ansiedade dos estudantes. Porém, como não se encontrou relação entre diminuição de ansiedade inicial e facilidade na elaboração e aplicação do plano de assistência de enfermagem, conclui-se que a orientação do estudante deve ser individual e contínua.

\section{REFERENCIAS BIBLIOGRAFICAS}

1. ALBIEZ, S.A. - Reflecting en the development of a relationship. Journal of Psychiatric Nursing, 8 (6): 25-7, nov. 1970.

2. BISCHOFF, M.W. \& CONNOLLY, M.G. - New skill are need. American Journal of Nursing, 51 (9): 567-8, sep. 1951.

3. BLACK, K. - Appraising the psychiatric patients nursing needs. American Journal of Nursing, 52 (6): 718-21, 1952.

4. BRILL, N.Q. - The importance of understanding yourself. American Journal of Nursing, 57 (10): 13256, oct. 1957.

5. BROWN, M.M. \& FOWLER, G.R. Psychodynamic nursing: a biosocial orientation. 4 ed., Philadelphia, W.B. Saunders, 1971. p. 115.

6. GARANT, C. - A basis for care. American Journal of Nursing, 72 (4): 699-701, apr. 1972.

7. HOFLING, C.K. et al. - Basic Psychiatric concepts in nursing. 2 ed. Phidadelphia, J.B. Lippinco:t, 1972. p. 10.

8. HUGHIE, B. - Behavior of psychiatric patients and staff disconfort. Nursing Research, 16 (1): 67-68, winter, 1967.
9. IRVING, S. - Basic psrchiatric nursing. Philadelphia, W.B. Saunders; 1973. p. 1-2.

10. KIMBALL, L. - Psychiatric Nursing: syllabus and workbook for student nurse. 2. ed. St. Louis, Mosby, 1958, p. 23.

11. LEWIS, J.A. - Reflections on self. American Journal of Nursing, 60 (6): 828-30, june, 1960.

12. MADDISON, D. et al. - Psychiatric nursing. 3 ed., Baltimore, Willians and Wilkins, 1970, p. 17.

13. MERENESS, D. - Essential of psychiatric nursing. 8 ed., St. Louis, Mosby, 1970, p. 28-33.

14. MULLER. T. G. - Fundamentals of psychiatric nursing. New Jersey, Littefield, Adams, 1971. p. 4-7.

15. ROBINSON. L. - Psychiatric nursing as a human experience. W.B. Saunders, Philadelphia, 1972, pg. $2-4,14$

16. STEVENS, L.F. - Understanding ourselves. American Journal of Nursing, 57 (8) : 1022-26, oct. 1957.

17. TUTER, W. - As you enter psychiatric nursing. American Journal of Nursing, 56 (1): 72,4, jan. 1956.

18. WALLACE, C.M. - Nursing the schizophrenic patient. Nursing Mirror, 127 (4): 36, jul. 1968. 
FUKUDA, I.M.K. e ARANTRS, E.C. - Dificuldades dos estudantes de enfermagem, frente aos doentes mentals internados. Rev. Bras. Enf.; DF, 28 : 48-63, 1976.

\section{ANEXO 1 \\ 1.0 QUESTIONARIO \\ (1.0 dia de aula)}

1. Que idéla você tem a respeito dos doentes mentais em geral?

2. Quais são seus sentimentos em relação aos doentes mentais?

3. Como você espera que vá ser a sua primeira experiência com os pacientes no hospital?

4. Você já entrou em contato com algum doente mental?

5. Se teve contato, como foi essa experiência?

\section{ANEXO 2}

\subsection{QUESTIONARIO}

(4. a semana)

O que você está sentindo, no momento, em relação aos pacientes em geral?

\section{ANEXO 3}

\section{ORIENTACAO}

1. Introdução:

Importância do autoconhecimento na identificação dos problemas do paciente, para o planejamento da assistência de enfermagem.

2. Fenômenos que ocorrem no relacionamento enfermeira-paciente, suas possíveis causas e conseqüências: Neste item, são abordados:

medo de ser agredido;

medo do envolvimento;

medo de o paciente não responder às perguntas;

medo de o paciente perceber a sua insegurança (teste);

medo de não ser útil;

medo de ficar doente;

medo de o paciente exigir demais;

rejeição;

envolvimento excessivo;

necessidade de aceitação;

manipulação por parte do paciente;

insegurança;

dificuldade em aceitar o paciente como pessoa;

dificuldade em aceitar o paciente como doente mental. 
FUKUDA, I.M.K. e ARANTSS, E.C. - Dificuldades dos estudantes de enfermagem, frente as doentes mentais internados. Rev. Bras Enf.; DF, 28 : 48-63, 1976.

ANEXO 4

PLANO DE ASSISTENCIA DE ENFERMAGEM

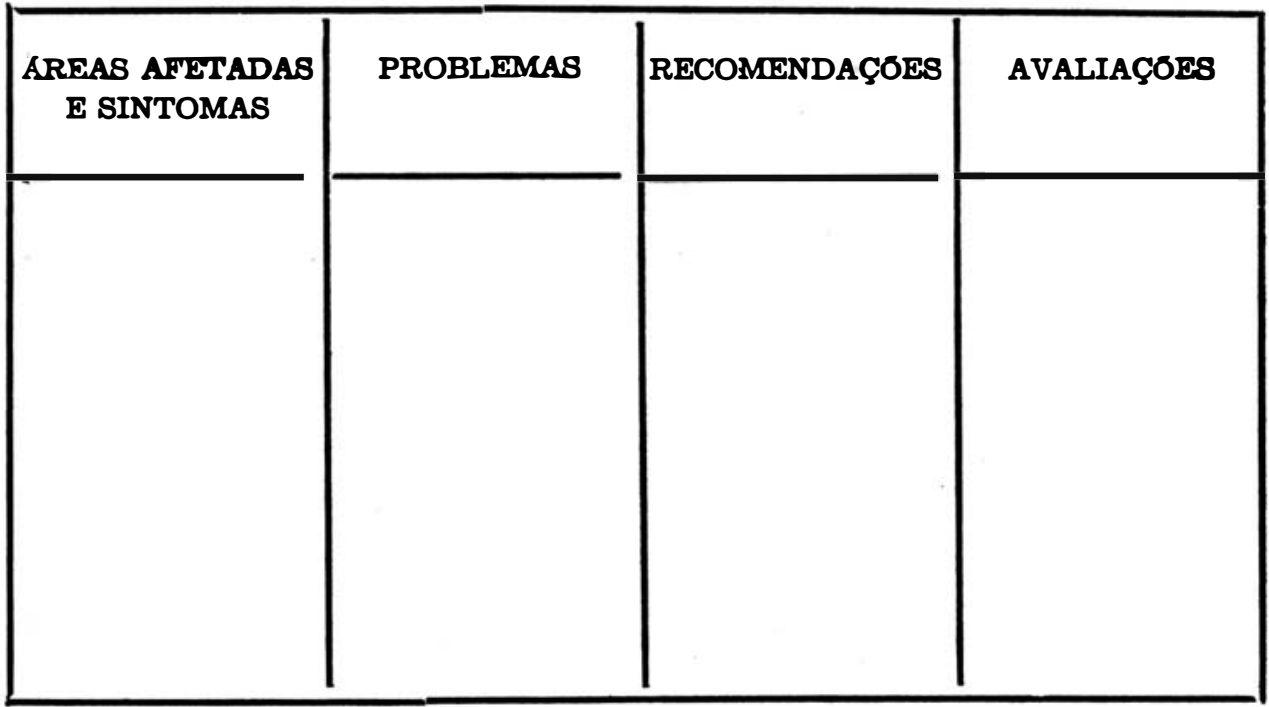

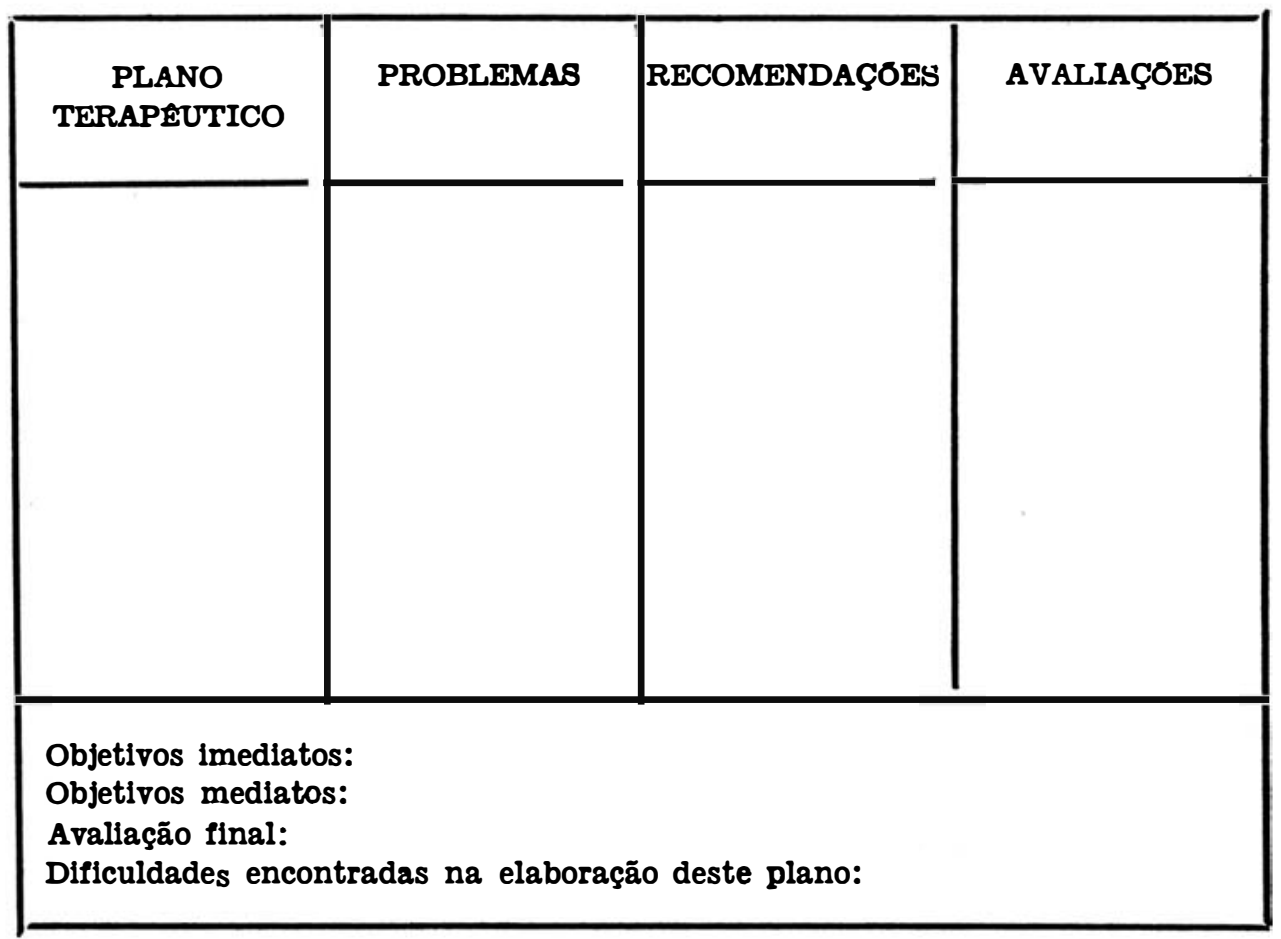


FUKUDA, I.M.K. e ARANTES, E.C. - Dificuldades dos estudantes de enfermagem, frente aos doentes mentais internados. Rev. Bras. Enf.; DF, 28 : 48-63, 1976.

\title{
ANEXO 5 \\ 3. QUESTIONARIO \\ (6. ${ }^{\mathrm{a}}$ semana)
}

O quo você está sentindo, no momento, em relação aos pacientes em geral?

\begin{abstract}
ANEXO 6
Como distúrbio de comportamento foram consideradas as seguintes expressōes:

comportamento não-aceito pela sociedade;

desajuste de comportamento;

comportamento considerado fora dos padrōes normais;

alteraçōes de comportamento;

comportamentos esquisitos;

comportamentos anormais;

Como ideia indefinida foram consideradas as seguintes:

"Doentes mentais são pessoas que não conseguiram superar barreiras da vida."

"São doentes, como qualquer outro, que necessitam de cuidados."

"São pessoas com estrutura psicológica alterada."

"São indivíduos que podem ser controlados, compreendidos e aceitos."

"São pessoas em crise catatônica."

"Já conhecia alguns tipos de doentes mentais."

"São indivíduos que não devem ser marginalizados, mas que devem ser ajudados."

"Os doentes mentais necessitam de cuidados especiais, muita atenção e paciência."

'Pessoas que reprimem sentimentos e necessitam ser compreendidas social e psicologicamente."

"São pessoas com problemas mentais e esses problemas se manifestam no seu comportamento."

"Pessoas mais doentes, que sofrem mais do que pessoas doentes fisicamente."
\end{abstract}

\section{ANEXO 7 \\ CLASSIFICAÇAO DOS SENTIMENTOS EXPRESSOS PELOS ESTUDANTES}

Como ansiedade foram consideradas as seguintes expressōes:

receio por desconhecer a psicopatologia;

receio de: permanecer junto ao paciente; nāo ser compreendido; 
FUKUDA, I.M.K. e ARANTES, E.C. - Dificuldades dos estudantes de enfermagem, frente aos doentes mentais internados. Rev. Bras. Enf.; DF, 28 : 48-63, 1976.

desconfiança;

insegurança;

medo de não ter tido contato com um doente mental;

medo do desconhecido;

medo de: ficar presa no hospital;

não conseguir relacionar-me;

não estar agindo corretamente;

não ser aceito;

vontade de deixar tudo de lado e sair correndo;

sensação de inutilidade e de incapacidade;

incerteza da cura do paciente;

frustração pelo pouco que se pode fazer;

ansiedade em geral;

pacientes agressivos, agitados, revoltados, desconfiados.

Como pena ficaram subentendidos:

dó;

compaixão;

vontade de ajudá-los;

apoio.

Foram consideradas como rejeição:

antipatia;

aversão;

raiva (ou desespero) por não saber o que fazer;

indiferença por nunca ter entrado em contato direto com doentes mentais;

vontade de largar o paciente no meio da conversa;

irritação;

frieza.

Foram considerados como curiosidade:

curiosidade em geral;

interesse em saber o porquê das reações do paciente.

Como aceitação foram consideradas as seguintes respostas:

compreensão;

sentir que pode ajudá-los, depois de treinado para tal;

sentir que pode ajudar de alguma forma, mesmo que não conheça nenhum caso;

carinho e dedicação;

amor. 
FUKUDA, I.M.K. e ARANTES, E.C. - Dificuldades dos estudantes de enfermagem, frente aos doentes mentais internados. Rev. Bras, Enf.; DF, 28 : 48-63, 1976.

Como sentimento indefinido foram consideradas as seguintes:

"Iguais aos outros da clínica médica e cirúrgica, só que com um pouco mais de tolerância."

'Os mesmos que para um doente comum que necessitasse de um tipo diferente de auxillo."

"De muito respeito humano."

"Sinto que precisam ser amados e compreendidos, assim como qualquer outra pessoa normal. Eles precisam acreditar que alguém se interessa por eles e que nosso objetivo não é o de caçoar deles, mas sim, de ajudar."

"Acho que devemos tratá-los com muita compreensão, carinho, sem ter pena, sem ter compaixão."

"São pessoas que necessitam de ajuda, sem se ter medo. Meus sentimentos, não sel."

"Sinto necessidade de tratá-los como pessoas humanas, auxilliando-os para uma recuperação mais rápida."

"Uma pessoa doente necessita de cuidados especificos."

"Acho que todos os pacientes precisam de amor."

"Atualmente estou me sentindo mais segura, quando abordo algum paciente ou sou abordada pelo mesmo."

"Vejo os doentes mentais como qualquer outro."

"Sinto que necessita de ajuda, apoio, de alguém que o possa ouvir."

"Não posso definir claramente. Acho que podem ser encarados como qualquer outra pessoa doente, acrescida dos problemas de relacionamento."

'Não sei como definir; só sel que gostaria de compreendê-los e poder ajudá-los."

"Sentimento de apoio, ajuda."

"Como gosto de dar atenção aos necessitados, os meus sentimentos sempre foram positivos."

"Conseguir entender os seus comportamentos."

"Necessidade de compreendê-los, ajudá-los."

ANEXO 8

Medo:

"Ful agredida várias vezes."

"Marcante, deixou-me transtornada."

"Bastante estranha, quase assustadora."

"Causou rejeiçāo."

"Medo de aproximar-me; para a maioria, o paciente representava um espetáculo à parte."

"O paciente era agitado, tinha olhar brilhante e fixo, falava muito sobre morte, sangue. Mostrava comportamento totalmente diferente do seu normal." 
FUEUDA, I.M.K. e ARANTES, E.C. - Dificuldades dos estudantes de enfermagem, frente aos doentes mentais internados. Rev. Bras. Enf.; DF, 28 : 48-63, 1976.

"No primelro instante, medo; após vários contatos, pena, por não haver nunca melhora por parte do doente."

"Uma puérpera com psicose puerperal, em tentativa de sulcídio. Na intenção de segurá-la, para que năo se atirasse do $4 .^{\circ}$ andar, caímos e fraturel o braço."

"A primeira impressão causou um impacto, que fol eliminado à medida que tive maior contato com eles.'

Pena:

Deprimente.

Pena.

Horrivel, revoltou pela maneira como eram tratados.

Reação indefinida:

"Era um rapaz com problema psíquico e não urológico. Tinha reações normais, frente aos problemas surgidos naquela clínica."

"Tratel-o como pessoa normal: o doente já estava em lase de alta médica."

"Só observei."

"Amizade difícil; porém, na época, achava apenas que o seu comportamento era maluco."

"Positiva por um lado e negativa por outro, porque năo sabia como iria ajudar."

"Observel e fui observada."

"Nāo tive contato, quando em crise."

"Experiência familliar.'

"Tenho um tio doente mental, que passa a maior parte do tempo em minha casa."

Afirmação de experiência positiva:

'Foi muito boa, pois serviu para desfazer uma idéia errada sobre os doentes mentais."

"Fol maravilhosa. Vi pessoas recuperando-se em poucos dias."

\section{ANEXO 9 \\ RESPOSTAS DA TERCEIRA PERGUNTA DO ANEXO 1}

\section{MANIFESTAÇÓES DE ANSIEDADE:}

"Imagino que será possível o relacionamento verbal e lógico."

"Terel que procurar e solicitar muito, para conversar com um paciente." "Espero compreender os problemas apresentados pelos pacientes, porém tenho receio de como reagirel, frente ao comportamento que poderel encontrar." 
FUKUDA, I.M.K. e ARANTES, E.C. - Dificuldades dos estudantes de enfermagem, frente aos doentes mentais internados. Rev. Bras. Enf.; DF, $28: 48-63$, 1976.

"Acho que não conseguirei comunicar-me com o paciente, na primeira experiência."

"Sinto que não serei aceita, na minha tentativa de compreendê-lo e ajudá-10."

"Triste."

"Deprimente."

"Com o medo que sinto, acho que não vou conseguir manter um clima normal, no primeiro contato."

"Traumatizante."

"Penso que terei um certo receio de aproximar-me dos pacientes."

'A ansiedade não me permite um raciocínio lógico, mas a idéia geral

é a de que será um fracasso total."

"Penso que vou ser agredido."

"Acho que não vou conseguir quase nada com os pacientes, porque acho que eles são indivíduos muito complexos."

"Desastrosa, porque estou com medo e insegurança."

"Experiência chocante e frustradora."

"Acho que sentirei medo e compaixão."

"Não sei, não posso aquilatar: sinto medo e insegurança."

"Penso que se desenvolverá um clima tenso para mim."

"Imagino que não me controlarei, emocionalmente, lá dentro."

"Penso que sentirei medo de fícar entre vários doentes."

"Tenho receio de querer ajudar, e prejudicar mais."

"Espero que seja algo anormal."

"Péssima."

"Não sel o porquê das coisas."

Expressão imprecisa:

"Penso que poderei entender o porquê de seus atos e pensamentos."

\section{ANEXO 10}

Dificuldades dos estudantes relativas ao comportamento do paciente.

\begin{tabular}{lr} 
& N.o \\
Repete muit.c as mesmas queixas & resp \\
Não menciona sua psicopatologia & 1 \\
Permanece cm silêncio durante a entrevista & 1 \\
Não aceita entrevista & 1 \\
Não aceita o estudante como profissional & 1 \\
Não se relaciona com as outras pessoas & 2 \\
Mantém-se fora da realidade & 6 \\
Não participa das atividades & 2 \\
Não fala, não conversa & 2 \\
Não prende a atenção naquilo que faz & 1 \\
O paciente não aceita a internaçăo & \multicolumn{1}{c}{ Total }
\end{tabular}


FURUDA, I.M.K. e ARANTES, E.C. - Dificuldades dos estudantes de enfermagem, frente aos doentes mentais internados. Rev. Bras. Enf.; DF, $28: 48-63,1976$.

Dificuldades dos estudantes relativas ao próprio conhecimento.

$$
\begin{aligned}
& \text { N. }{ }^{\circ} \text { de } \\
& \text { respostas }
\end{aligned}
$$

Identificar os problemas do paciente

Falta de conhecimento sobre sintomas, tratamentos e evolução da moléstia

Identificar as áreas afetadas

1

4

1

1

1

2

1

1

1

1

17

Dificuldades dos estudantes relativas ao próprio estado emocional.

N.o de

respostas

Chamar o paciente de "senhor"

1

Não aceitar o paciente como doente

1

Anotar as comunicações percebidas

1

Ter medo de ser rejeitado

2

Encontrar assunto para manter conversação agradável

1

Sentir pena do paciente 